\title{
Days of Our Lives
}

\author{
Family Experiences of Digital Technology Use
}

\author{
Eleanor Chin Derix \\ Interaction Design and Human Practice Lab \\ Faculty of Engineering and IT \\ University of Technology Sydney, NSW, Australia \\ eleanor.c.derix@student.uts.edu.au
}

\author{
Tuck Wah Leong \\ Interaction Design and Human Practice Lab \\ Faculty of Engineering and IT \\ University of Technology Sydney, NSW, Australia \\ tuckwah.leong@uts.edu.au
}

\begin{abstract}
This paper describes findings from a workshop, with 11 parents of children under 12 years of age, that explored family experiences of digital technology use. We found that technology experiences within everyday family life are complicated and interlinked. We highlight four experiences that featured most prominently with our participants: apprehension, ambivalence, compromise and conflict. In addition, we discuss how family values govern these experiences and how families use digital technology. This work contributes to current understandings of how family values guide technology practices. These early findings suggest that deeper understandings of family values; how they are shared, negotiated and put into action, will help inform the design of future technologies that not only support families' practices and activities, but also their experiences and aspirations.
\end{abstract}

\section{CCS CONCEPTS}

- Human-centered computing $\rightarrow$ Human computer interaction (HCI)

\section{KEYWORDS}

Digital technology, family, experiences, values.

\section{ACM Reference format:}

E.C. Derix and T.W. Leong. 2018. OzCHI Proceedings Paper in word Format. In Proceedings of ACM OzCHI conference, Melbourne, Australia, December 2018 (OzCHI 2017), 6 pages. https://doi.org/10.1145/3292147.3292185

\section{INTRODUCTION}

$\mathrm{HCI}$ research into the pervasive use of technology in family life has shown how digital technology has affected the minutiae of family life. Digital technologies, such as smartphones and tablets, have become a mainstay of today's families. The proliferation of mobile devices has blurred the work and home lives of parents
$[30,38]$, and they are increasingly relied upon to manage prosaic aspects of domestic life [15]. Even the use of touchscreen devices by toddlers and babies has been normalized [20,35]. Meanwhile, debates and uncertainty endure over how the presence and use of these devices are affecting aspects of family life $[6,46]$.

Amidst the profusion of digital technologies into families and uncertainties regarding its effects, many researchers have urged for a deeper understanding of ever-evolving family experiences of technology use $[10,16,18,43]$. This will be more critical, with the emergence of Internet of Things (IoT) and Voice User Interface (VUI) devices that are set to join the current device ecosystems of family homes. These emergent technologies amplify uncertainties over issues such as privacy, security and ownership, further complicating family experiences [32, 34, 42].

It is against such a backdrop that we sought to explore how today's families are experiencing their digital technology use. As we will explain in Related Work, efforts to date have tended to limit their focus to particular family members or specific family practices or activities. Our workshop sought to capture a broader view of how digital technology is incorporated and experienced in all aspects of everyday family life. The aim was to establish some early findings of family experiences of digital technology use, and to surface productive directions for future research.

\section{RELATED WORK}

As digital technologies have increasingly become part of the home and families [15, 27], HCI researchers have explored how digital technology can support family practices, relationships and experiences. One common approach in $\mathrm{HCI}$ involves the design and introduction of (novel) digital technologies to try and improve particular aspects of family life. These interventions include video connections to enhance experiences of families communicating over distance [22], a location-aware clock to improve experiences of home coordination [7], and even technologies to enrich experiences within intimate relationships [14]. While many seek out opportunities to exploit digital technologies to support practices and experiences in families, there are others who warn that digital technology use within today's families is problematic $[43,46]$.

There are suggestions that pervasive use of technology in childhood can adversely affect child development $[6,23]$, and that parents' prolific use of technology reduces their ability to attend to the needs of their children [46]. Unsurprisingly, pediatricians and psychologists have weighed into these claims. For example, the American Academy of Pediatrics issued screen-time guidelines, 
associating use in early childhood with greater risk and recommending age-dependent limits [1]. Meanwhile, psychologists report on how technology-based interruptions, or "technoference", adversely affect family relationships, and associate parents' device use with problematic behavior in young children [31]. Amplified by mainstream media [8, 24], such reports fuel widespread uncertainty amongst laypeople around the effects of technology use in families [6]. Some in HCI are trying to understand this apparent 'darker side' of technology use in the family [5, 18, 19, 29, 37].

To address concerns over excessive use in childhood, efforts have been made to explore the implementation of parental controls and family technology rules. Research into the effect of rules on relationships and experiences has tended to focus on specific activities, such as video gaming [41] and internet use [28]. Since the widespread adoption of touchscreens, an initial focus on adolescents has expanded to include technology use in early childhood $[13,19,47]$. Research into controlling childhood technology use tends to consider a parent's role as the guardian of their child's technology use. A prominent exception is Hiniker et al's [17] work on technology rules that also considers the role of parents as technology users. This found that both parents and children struggle to comply with rules, leaving all family members desiring more attention from one another when in each other's company. The authors call for further work to explore contextually appropriate use of technology within families.

The role of parents as users of technology has received increasing attention in recent years. Palen's [38] study found mobile devices enabled 'remote mothering' and shifted family members' sense of 'home' as a place. The affordances of mobile devices have since expanded far beyond telephony. With Facebook's first teenage users now maturing into parents, mothers have become the fastest growing demographic of social media users [36]. In turn, researchers demonstrate a growing interest in parents' use of technology, particularly of social networking sites (SNS) [3, 12, 25, 44, 45]. These studies reveal that while considering their own technology use, parents' experiences remain governed by their responsibilities as parents and the need to consider their child. For instance, parents report negative emotional experiences, including guilt, when they use their smartphone whilst caring for their children at public playgrounds [18]. Parents also describe struggles to consider issues such as child privacy, when deciding what information to share about their child online [2].

In summary, our review of related work in HCI found that efforts tend to limit their focus to the experiences of parents $[3,4,18,25$, $44,45]$ or children $[5,6,35,39]$. As Isola and Fails note in their literature survey of technology use in family [21], very little work explores experiences of the family as a whole; recommending that future work should adopt a more holistic view of family. Within the limited research that does consider the experiences of both parents and children, they focus on particular situations, such as mealtimes [9, 11, 37], particular devices, such as mobile phones [37] and home assistants [40], and particular practices, such as rules to restrict family technology use $[17,29]$. However, the range of digital technologies used in families today is broad and increasingly growing; often used by all members of the family. Given the uncertainties that surround the effects of technology use on family experiences, we need to develop more nuanced understandings of the experiences of families as a whole, especially within the complex and messy nature of everyday family life. As a first step towards this goal, we conducted a workshop with parents of young children, to understand these experiences. The workshop was granted ethics approval from University of Technology Sydney.

\section{WORKSHOP}

The activities of the two-hour workshop were informed by our review of related literature. This included ways to explore how digital technology is experienced by all family members, which devices were typically used, when, where and why. Importantly, we explored participants' feelings towards these experiences, as well their perception of how their family members felt.

\subsection{Participants}

The workshop consisted of 11 parents from nine Sydney households with ethnically diverse backgrounds. These parents, of children ranging between 9 months and 9 years old, had varied technological expertise and a broad spectrum of technology outlooks - from self-proclaimed 'futurists' to those declaring they were cautious and apprehensive (Table 1).

\begin{tabular}{|l|l|l|l|l|l|}
\hline & M/F & Age & Relationship & $\begin{array}{l}\text { Employment Type } \\
\text { (Full/Part-Time/ } \\
\text { Home Duties) }\end{array}$ & $\begin{array}{l}\text { Children } \\
\text { No. (age) }\end{array}$ \\
\hline P1 & M & 38 & Married & Architecture (FT) & $2(3,<1)$ \\
\hline P2 & F & 36 & Married & Architecture (PT) & $1(2)$ \\
\hline P3 & F & 42 & Widowed & Planner (FT) & $3(8,7,5)$ \\
\hline P4 & F & 40 & Single & Pharmacist (PT) & $2(6,3)$ \\
\hline P5 & F & 30 & Married (P8) & Home Duties (HD) & $3(5,3,<1)$ \\
\hline P6 & F & 37 & Married & Marketing (PT) & $2(3,1)$ \\
\hline P7 & M & 52 & Married & Marketing (PT) & $2(9,6)$ \\
\hline P8 & M & 33 & Married (P5) & Project Manager (FT) & $3(5,3,<1)$ \\
\hline P9 & F & 47 & Married & IT (FT) & $2(6,2)$ \\
\hline P10 & F & 35 & Single & Child-Care (PT) & $1(9)$ \\
\hline P11 & M & 40 & Married & Home Duties (HD) & $2(8,6)$ \\
\hline
\end{tabular}

Table 1: Summarized participant details

\subsection{Workshop Activities \& Data}

The workshop began with an Icebreaker introduction exercise to capture an overview of technology attitudes and practices. Three activities followed. Each required a worksheet to be completed individually before discussing experiences as a group. The first activity asked about Positive Technology Experiences in family life. The second activity, Love/Hate, explored issues of ambivalence. Participants were asked to consider family experiences of digital technology use that were felt to have both positive and negative aspects. The final activity, That's Not OK, asked about family experiences with technology that were felt to be negative or inappropriate. We provided participants with inspirational picture cards. During the first two activities, these depicted a range of prevalent digital technologies (e.g. smartphones, home assistants etc.). During the third activity, various family contexts of technology use were shown (e.g. families making a video call together, parents trying to remove a device from a child etc.).

Audio and video recordings of the workshop were transcribed. Thematic analysis [33] was used to analyze the transcripts and the completed activity sheets. This produced different pertinent themes, which we will describe next. 


\section{FINDINGS: “IT'S COMPLICATED”}

Despite the group's diverse backgrounds, common themes emerged. Participants described a wide range of experiences: positive, negative and those in-between. We highlight four prominently discussed experiences that reveal the complicated nature of family life. Whilst they are discussed separately, the experiences are interlinked, shaping and influencing each other.

\subsection{Apprehension}

Participants described how their attitudes towards digital technology had changed since becoming parents, becoming more apprehensive. This was due to two main factors. Firstly, concerns over potential adverse effects on children's social, emotional or physical development, as a result of excessive or inappropriate technology use in childhood. Secondly, considerations of children's privacy, safety and identity ownership. These factors contribute to feelings of uncertainty that parents have regarding family technology use. For example, P1, a father of two young kids whose work involves digital technology explained, "it (is) weird...I'm very interested (in technology) professionally, and personally, but...I don't really know yet what I think when it come to my kids". Therefore, parents are more hesitant, especially when deciding whether to adopt new technologies. For instance, P1's concerns over his children's privacy had so far prevented him from purchasing a VUI home assistant.

Due to these feelings of apprehension, all participants believed family technology rules were required. However, none had a clear process of setting, managing, or enforcing technology rules. As a result, participants felt unable to fulfill their expectations of themselves as parents. For example, "So I'm quite cautious, particularly since Max has come along... we've tried to set up tech values...but it doesn't work" (P2). Participants often looked ahead, considering how they would incorporate future technologies with added apprehension, "we are probably going into a bit of a minefield as they grow up”(P6).

\subsection{Ambivalence}

Although we planned to discuss ambivalent experiences during Activity 2, participants already began sharing their experiences of ambivalence during their introductions. For example, P9, who works in IT, described her attitudes to technology, "I' $m$ a bit apprehensive about it, though I do love it...I'm at home mostly with the kids, and I do appreciate their appreciation of technology, so I can do the dishes, or whatever". She added, "I'm enthusiastic about digital technology as a concept...but I'm not so enthusiastic about it at home".

Other examples of ambivalence were found as participants unwittingly contradicted views they had shared earlier in the session. For instance, P6, began the session by describing her use of SNS as a positive experience "Mindless scrolling...there's something quite therapeutic about that, just thinking about everything and nothing". But towards the end of the session, she claimed, "the time wasting of...social media...I think it makes you a bit stupid, and a bit unbalanced".

Ambivalence was found to pervade and affect all of the other experiences shared by our participants.

\subsection{Compromise}

Participants described how their families' use of digital technology compromised aspects of their children's upbringing. For instance, P3, who had described her use of mobile news, online shopping and online banking, as positive experiences, added, "the flip-side of that, is that while its great and convenient for me, I worry that my kids are missing out...they are not coming to the bank with me, they are not learning the money...they are not seeing that I am reading the newspaper, and not playing a game... whereas I grew up seeing my parents reading newspapers and learning that they were valuable and important". Interestingly, P7, a self-declared 'technologist and futurist' stated, "I prefer to take (the kids) shopping with me for the real experience...its actually some time that we get to spend together".

Questions were also raised over the individual and curated nature of online experiences. P3 reflected, "how individually tailored it all is, particularly with my kids. They get used to, 'Well I want to watch MY things', and I have 3 kids all wanting to watch separate things...it's (about) them learning to...share and...do things collectively as a group". She also questioned how her children's access to online knowledge might be altering her role, "I get a bit sick of it (technology) being right all the time. You used to be the fountain of all knowledge, now they are like 'No Mum, you're wrong'. I used to be able to con them on lots of things, now they can look it up, they don't have that relationship with you that you are always right".

\subsection{Conflict}

Disagreements over device use were cited as a main source of negative experiences with technology. Whilst disputes between parents and children were mentioned, the differing approaches between parents were more vehemently discussed. P5 presented herself as "lenient...my husband is very strict". P9 added, "My wife is very strict, so there is a conflicting approach, which is tough on the kids". Conflict between parents and children often escalated within the family when parents held differing parenting attitudes towards children's technology use. Parents also disapproved of each other's behavior, such as P9's condemnation of her wife's habit of shopping online while at the dinner table, "I can't stand $i t$ ", she declared.

Internal conflict was also discussed, mainly by mothers, who admitted being unable to adhere to their own rules. For example, when discussing negative experiences, $\mathrm{P} 3$ explained "my big (rule) that's not $O K$ in front of the kids, is screens in bed, but then I end up doing the same thing in bed once they're asleep, and very often they are asleep with me in my bed while I am secretly watching!" P5 also reflected on her ability to stick to her own rules "putting my phone before my children's needs...I'm guilty of all of this, I can't even read this, I feel bad...I'm sitting there on my phone. I should be able to put it aside, for the kids". P6 referred to her past behavior, "Breastfeeding my child and checking my phone... that was the time you should be talking to your child. So (I felt) conflicted as I was always doing that". P6 also said that she found managing family technology use to be harder than any other parenting issue. P9 concurred, "it's so prevalent, you deal with it as it comes up but it's everywhere ...it's about everything you do". 


\section{DISCUSSION}

Like others [27], our participants' stories reveal the complicated nature of their felt and lived experiences with technology within the messiness of everyday family life. In particular, our participants' experiences were strongly shaped by their family values. The values that emerged from these stories included togetherness, privacy, freedom and parental responsibility. The value that was discussed most by our participants was togetherness. Given the constraints of this short paper, we will focus on togetherness, to discuss how family values shape experiences.

Our participants generally describe family life as busy. Parents repeatedly express a desire to spend 'family time' with partners and children, in which to share a sense of togetherness. As such, technology use that promotes togetherness is described as a positive experience. In contrast, technology use that diminishes togetherness is described as a negative experience. For example, P3 enjoys the convenience of online shopping and banking, as she feels it enables her to spend more time with her family. On the other hand, P9 dislikes her wife's habit of shopping online during family mealtimes, as she feels it reduces togetherness.

People's values drive their behavior [15] and even an individual's decision on whether or not to adopt and use certain technologies [26]. However, our findings reveal a more complicated situation of 'values in action' in family life. This is because all individual family members contribute to putting shared family values into action. However, individual values might not always align. In order to establish shared family values, individual values need to be communicated and negotiated. Prior research has explored experiences of conflict between parents and children associated with technology use $[5,19]$. Stories from our workshop also reveal recurrent conflicts of values between parents, with regards to technology use. Conflicts arise when parents' approach to children's technology use differs, or when they disapprove of each other's technology use. More attention is paid to a partner's use of technology in situations when children are present. Additionally, parents experience internal conflict when their own use of technology disregards rules that they have enforced on family members. We are not aware of any prior work exploring the range of conflict experienced within families as a result of technology use.

The presence and use of technology in families can create conflicts in values. Our participants' reports of ambivalent and compromised experiences highlight the extent to which a particular use of technology can promote certain family values, whilst simultaneously undermining others. It is possible for compromises to only become evident over time, such as when parents perceive a lag in their child's development. It might also be that individual family members benefit, at the expense of others. An example of this can be seen, in P5's admission of 'putting my phone before my children's needs'. This leads to attempts to balance individual values with shared family values. This can become complicated, particularly since parents are both users of technology and guardians of their children's technology use. Parents attempt to restrict their own use of technology, in order to prioritize the needs of their children. Researchers have shown that parents limit their device use at times when children are present, such as mealtimes [37] or at children's playgrounds [18]. For some of our participants, they have gone further and their prioritization of family values has led to them deliberately opting out of using a particular technology that they enjoy as an individual. For example, instead of online banking or shopping, parents physically take their kids to the bank or supermarket in order to teach them about certain aspects of money or food. In fulfilling their parental responsibility, these parents forgo their desire for convenience.

Family values govern how experiences of technology use are evaluated, yet the ways in which family values are put into action can vary between families. Though guided by the same family value, different families adopt different family practices. So, while several participants used online shopping to free up time to support togetherness, others felt that a trip to the shops with their kids was, in fact, an opportunity for togetherness.

Research into ageing individuals' values has described how people's values are dynamic, open to negotiation and change over time to best fit in with their new and changed life circumstances [26]. This resonates with the stories we heard, revealing that people's attitudes towards technology change when they become parents. While researchers note parents' concern over different aspects of technology use $[2,5]$ and are increasingly exploring the use of technologies, such as SNS, by new parents[12, 44], we have not found research that explicitly describe how values and attitudes change as individuals transition into parenthood. Nor have we found any explorations of how family experiences of technology change over time. However, we found that any rules and boundaries associated with technology use need to be continually revisited, renegotiated and even revised as children become older. This need is furthered by the availability, adoption and incorporation of ever-new devices into family life.

In addition, we discovered emergent associations between primary caregivers and their experiences of family technology use. In our workshop, most primary caregivers were mothers. They confessed to having a more lenient parenting approach to technology, compared to their partners who were described as strict. All the stories we heard of internal conflict, guilt and regret resulting from family technology use were from mothers. This possibly hints at influences of gender with regards to values pertaining to technology use. After all, the approach of mothers and fathers to particular aspects of technology use has been found to differ [2]. These differences require parents to discuss and negotiate certain aspects of technology use. We certainly encourage more sensitive and considered work to better understand if and how gender roles affect family values in action, and resulting experiences of family technology use.

In closing, we must qualify that our study was constrained to a short workshop with 11 participants. Nevertheless, it provides a glimpse into the complicated experiences of today's family experiences of digital technology, including the uncertainties regarding adverse effects on children. This paper also offers an emergent understanding of how these experiences are shaped by people's values. Our findings strongly suggest that the design of future technologies, intended for use by families, would benefit from deeper, richer, and more nuanced understanding of how family values are established, negotiated, change over time, and are put into action with regards to technology use. Through this, we might design technologies that are more supportive of family values, and desired experiences. 


\section{REFERENCES}

[1] AAP. 2018. Family Media Plan. Retrieved April 18, 2018 from https://www.healthychildren.org/English/media/Pages/default.asp $\mathrm{x}$.

[2] Tawfiq Ammari, Priya Kumar, Cliff Lampe and Sarita Schoenebeck. 2015. Managing children's online identities: How parents decide what to disclose about their children online. In Proceedings of the 33rd Annual ACM Conference on Human Factors in Computing Systems. ACM, 1895-1904.

[3] Tawfiq Ammari and Sarita Schoenebeck. 2015. Understanding and supporting fathers and fatherhood on social media sites. In Proceedings of the 33rd Annual ACM Conference on Human Factors in Computing Systems. ACM, 1905-1914.

[4] Madeline Balaam, Judy Robertson, Geraldine Fitzpatrick, Rebecca Say, Gillian Hayes, Melissa Mazmanian and Belinda Parmar. 2013. Motherhood and HCI. In Proceedings of CHI'13 Extended Abstracts on Human Factors in Computing Systems. ACM, 3215-3218.

[5] Lindsay Blackwell, Emma Gardiner and Sarita Schoenebeck. 2016. Managing expectations: Technology tensions among parents and teens. In Proceedings of the 19th ACM Conference on ComputerSupported Cooperative Work \& Social Computing. ACM, San Francisco, California, USA, 1390-1401. DOI: http://dx.doi.org/10.1145/2818048.2819928

[6] danah boyd. 2014. It's Complicated: The Social Lives of Networked Teens. Yale University Press.

[7] Barry Brown, Alex S. Taylor, Shahram Izadi, Abigail Sellen, Joseph Jofish' Kaye and Rachel Eardley. 2007. Locating family values: a field trial of the Whereabouts Clock. In: J. Krumm, G.D. Abowd, A. Seneviratne, T. Strang (Eds.) 2007. Ubiquitous Computing. UbiComp 2007. Lecture Notes in Computer Science, vol 4717. Springer, Berlin.

[8] Rowan Davies. 2017. Is our smartphone addiction damaging our children? Retrieved July 2018, 2018 from https://www.theguardian.com/commentisfree/2017/may/31/smart phone-addiction-children-research-technoference-child-behaviour.

[9] Hilary Davis, Hasan Shahid Ferdous and Frank Vetere. 2017. 'Table manners': Children's use of mobile technologies in family-friendly restaurants. In Proceedings of the 2017 CHI Conference Extended Abstracts on Human Factors in Computing Systems. ACM, Denver, Colorado, USA, 969-978. DOI: http://dx.doi.org/10.1145/3027063.3053353

[10] Jerry Fails, Mona Leigh Guha, Michael Horn and Sara Isola. 2012. Technology for today's family. In Proceedings of CHI '12 Extended Abstracts on Human Factors in Computing Systems. ACM, Austin, Texas, USA, 2739-2742. DOI: http://dx.doi.org/10.1145/2212776.2212709

[11] Hasan Shahid Ferdous, Bernd Ploderer, Hilary Davis, Frank Vetere and Kenton O'Hara. 2015. Pairing technology and meals: A contextual enquiry in the family household. In Proceedings of the Annual Meeting of the Australian Special Interest Group for Computer Human Interaction. ACM, Parkville, VIC, Australia, 370379. DOI: http://dx.doi.org/10.1145/2838739.2838780

[12] Lorna Gibson and Vicki L. Hanson. 2013. Digital motherhood: How does technology help new mothers? In Proceedings of the SIGCHI Conference on Human Factors in Computing Systems. ACM, 313-322.

[13] Wendy W.L. Goh, Susanna Bay and Vivian Hsueh-Hua Chen. 2015. Young school children's use of digital devices and parental rules. Telematics and Informatics 32, 4, 787-795.

[14] Konstantinos Grivas. 2006. Digital selves: Devices for intimate communications between homes. Personal Ubiquitous Computing. 10, 2-3, 66-76. DOI: http://dx.doi.org/10.1007/s00779-005-0003-1

[15] Richard Harper, Tom Rodden, Yvonne Rogers and Abigail Sellen (Ed.). 2008. Being Human: Human-Computer Interaction in the Year 2020. Microsoft Research

[16] Katherine M. Hertlein. 2012. Digital dwelling: Technology in couple and family relationships. Family Relations 61, 3, 374-387.

[17] Alexis Hiniker, Sarita Y. Schoenebeck and Julie A. Kientz. 2016 Not at the dinner table: Parents' and children's perspectives on family technology rules. In Proceedings of the 19th ACM Conference on Computer-Supported Cooperative Work \& Social Computing. ACM, 1376-1389.

[18] Alexis Hiniker, Kiley Sobel, Hyewon Suh, Yi-Chen Sung, Charlotte P. Lee and Julie A. Kientz. 2015. Texting while parenting: How adults use mobile phones while caring for children at the playground. In Proceedings of the 33rd Annual ACM Conference on Human Factors in Computing Systems. ACM, 727-736.

[19] Alexis Hiniker, Hyewon Suh, Sabina Cao and Julie A. Kientz. 2016. Screen time tantrums: How families manage screen media experiences for toddlers and preschoolers. In Proceedings of the 2016 CHI Conference on Human Factors in Computing Systems. ACM, San Jose, California, USA, 648-660. DOI: http://dx.doi.org/10.1145/2858036.2858278

[20] Juan Pablo Hourcade, Sarah L Mascher, David Wu and Luiza Pantoja. 2015. Look, my baby is using an iPad! An analysis of YouTube videos of infants and toddlers using tablets. In Proceedings of the 33rd Annual ACM Conference on Human Factors in Computing Systems. ACM, 1915-1924.

[21] Sara Isola and Jerry Alan Fails. 2012. Family and design in the IDC and CHI Communities. In Proceedings of the 11th International Conference on Interaction Design and Children. ACM, Bremen, Germany, 40-49. DOI: http://dx.doi.org/10.1145/2307096.2307102

[22] Tejinder K. Judge, Carman Neustaedter and Andrew F. Kurtz. 2010. The family window: The design and evaluation of a domestic media space. In Proceedings of the SIGCHI Conference on Human Factors in Computing Systems. ACM, Atlanta, Georgia, USA, 23612370. DOI: http://dx.doi.org/10.1145/1753326.1753682

[23] Nicholas Kardaras. 2016. Glow Kids: How Screen Addiction Is Hijacking Our Kids - and How to Break the Trance. St. Martin's Press,

[24] Nicholas Kardaras. 2017. It's 'digital heroin': How screens turn kids into psychotic junkies. Retrieved July 18, 2018 from https://nypost.com/2016/08/27/its-digital-heroin-how-screensturn-kids-into-psychotic-junkies/.

[25] Priya Kumar and Sarita Schoenebeck. 2015. The modern day baby book: Enacting good mothering and stewarding privacy on facebook. In Proceedings of the 18th ACM Conference on Computer Supported Cooperative Work \& Social Computing. ACM, 1302-1312.

[26] Tuck Wah Leong and Toni Robertson. 2016. Voicing values: Laying foundations for ageing people to participate in design. In Proceedings of the 14th Participatory Design Conference: Full papers - Volume 1. ACM, Aarhus, Denmark, 31-40. DOI: http://dx.doi.org/10.1145/2940299.2940301

[27] Sonia Livingstone. 2007. On the material and the symbolic: Silverstone's double articulation of research traditions in new media studies. New Media \& Society 9, 1, 16-24.

[28] Sonia Livingstone and Ellen J. Helsper. 2008. Parental mediation of children's internet use. Fournal of Broadcasting \& Electronic Media 52, 4, 581-599. DOI: http://dx.doi.org/10.1080/08838150802437396

[29] Melissa Mazmanian and Simone Lanette. 2017. Okay, one more episode: An ethnography of parenting in the digital age. In Proceedings of the 2017 ACM Conference on Computer Supported Cooperative Work and Social Computing. ACM, 2273-2286.

[30] Melissa Mazmanian, Wanda J Orlikowski and JoAnne Yates. 2013. The autonomy paradox: The implications of mobile email devices for knowledge professionals. Organization Science 24, 5, 1337-1357.

[31] Brandon T. McDaniel and Jenny S. Radesky. 2018. Technoference: Longitudinal associations between parent technology use, parenting stress, and child behavior problems. Pediatric Research, 1.

[32] Emily McReynolds, Sarah Hubbard, Timothy Lau, Aditya Saraf, Maya Cakmak and Franziska Roesner. 2017. Toys that listen: A study of parents, children, and internet-connected toys. In Proceedings of the 2017 CHI Conference on Human Factors in Computing Systems. ACM, 5197-5207.

[33] Yohan Moon, Ki Joon Kim and Dong-Hee Shin. 2016. Voices of the internet of things: An exploration of multiple voice effects in 
smart homes. In Proceedings of International Conference on Distributed, Ambient, and Pervasive Interactions. Springer, 270-278.

[34] Miriam Morante, Maria Costa and Nuria Rodriguez. 2016. Children's evolving capabilities in their interaction with touchable devices from birth to 2 years old. In Proceedings of the The 15th International Conference on Interaction Design and Children. ACM, 560-564.

[35] Meredith Ringel Morris. 2014. Social networking site use by mothers of young children. In Proceedings of the 17th ACM conference on Computer supported cooperative work \& social computing. ACM, 1272-1282.

[36] Carol Moser, Sarita Y. Schoenebeck and Katharina Reinecke. 2016. Technology at the table: Attitudes about mobile phone use at mealtimes. In Proceedings of the 2016 CHI Conference on Human Factors in Computing Systems. ACM, 1881-1892.

[37] Leysia Palen and Amanda Hughes. 2007. When home base is not a place: Parents' use of mobile telephones. Personal Ubiquitous Computing. 11, 5, 339-348. DOI: http://dx.doi.org/10.1007/s00779006-0078-3

[38] Lydia Plowman, Joanna McPake and Christine Stephen. 2010. The technologisation of childhood? Young children and technology in the home. Children \& Society 24, 1: 63-74.

[39] Martin Porcheron, Joel E. Fischer, Stuart Reeves and Sarah Sharples. 2018. Voice interfaces in everyday life. In Proceedings of the 2018 CHI Conference on Human Factors in Computing Systems. ACM, Montreal QC, Canada, 1-12. DOI: http://dx.doi.org/10.1145/3173574.3174214

[40] Janet C. Read, Matthew Horton, Suzanne Clarke, Rhia Jones, Dan Fitton and Gavin Sim. 2018. Designing for the 'at home' experience of parents and children with tablet games. In Proceedings of the 17th ACM Conference on Interaction Design and Children. ACM, Trondheim, Norway, 441-448. DOI: http://dx.doi.org/10.1145/3202185.3202769

[41] Michael S. Rosenwald. 2017. How millions of kids are being shaped by know-it-all voice assistants. Retrieved April 10, 2018 from https://www.washingtonpost.com/local/how-millions-of-kids-arebeing-shaped-by-know-it-all-voiceassistants/2017/03/01/c0a644c4-ef1c-11e6-b4ffac2cf509efe5 story.html?noredirect $=$ on\&utm term $=$. d6cee3c8dfee.

[42] Diane J. Schiano, Christine Burg, Anthony Nalan Smith and Florencia Moore. 2016. Parenting digital youth: how now? In Proceedings of the $2016 \mathrm{CHI}$ Conference Extended Abstracts on Human Factors in Computing Systems. ACM, San Jose, California, USA, 3181-3189. DOI: http://dx.doi.org/10.1145/2851581.2892481

[43] Austin L. Toombs, Kellie Morrissey, Emma Simpson, Colin M. Gray, John Vines and Madeline Balaam. 2018. Supporting the complex social lives of new parents. In Proceedings of the 2018 CHI Conference on Human Factors in Computing Systems. ACM, 420.

[44] Diego Trujillo-Pisanty, Abigail Durrant, Sarah Martindale, Stuart James and John Collomosse. 2014. Admixed portrait: reflections on being online as a new parent. In Proceedings of the 2014 Conference on Designing Interactive Systems. (DIS '14). ACM, New York, NY, USA, 503-512. DOI: https://doi.org/10.1145/2598510.2602962.

[45] Sherry Turkle. 2016. Reclaiming Conversation: The Power of Talk in a Digital Age. Penguin,

[46] Elizabeth A. Vandewater, Seoung-Eun Park, Xuan Huang and Ellen A. Wartella. 2005. "No-you can't watch that" Parental rules and young children's media use. American Behavioral Scientist 48, 5: 608-623. 